Revue des patrimoines

$20 \mid 2013$

Les patrimoines de la traite négrière et de l'esclavage

\title{
La mise en ligne du Guide des sources sur la traite négrière (2008-2011)
}

Jean-Baptiste Auzel

\section{OpenEdition}

Journals

Édition électronique

URL : http://journals.openedition.org/insitu/10263

DOI : 10.4000/insitu.10263

ISSN : $1630-7305$

Éditeur

Ministère de la culture

Référence électronique

Jean-Baptiste Auzel, « La mise en ligne du Guide des sources sur la traite négrière (2008-2011) », In Situ [En ligne], 20 | 2013, mis en ligne le 14 mars 2013, consulté le 25 avril 2019. URL : http:// journals.openedition.org/insitu/10263; DOI : 10.4000/insitu.10263

Ce document a été généré automatiquement le 25 avril 2019

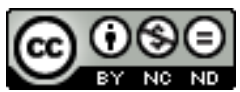

In Situ Revues des patrimoines est mis à disposition selon les termes de la licence Creative Commons Attribution - Pas d'Utilisation Commerciale - Pas de Modification 4.0 International. 


\title{
La mise en ligne du Guide des sources sur la traite négrière (2008-2011)
}

\author{
Jean-Baptiste Auzel
}

1 Le Guide des sources étant paru en 2007 sur papier, le ministère de la Culture et de la Communication a réfléchi aussitôt à le mettre sous forme numérique : dès janvier 2008. Cette éventualité est aussitôt adoptée par les Archives de France qui confient le projet à Pauline Moirez, conservatrice au département des publics. Pour cette opération, le ministère assurait un financement à hauteur de $10000 €$.

2 Ce qui fut décidé en 2008, ce fut non pas de faire un site de plus au sein du ministère, mais de présenter le guide comme une rubrique dédiée du site des Archives de France, ce qu'il est encore aujourd'hui (http://www.archivesdefrance.culture.gouv.fr/chercher/ esclavage).

3 D'un point de vue scientifique, on reprenait les mêmes informations qui figuraient dans le guide papier, avec le même respect des normes archivistiques internationales (ISAD/G ; ISAAR/CPF), à savoir une présentation par producteur et par fonds d'archives, et ensuite par niveaux de description (jusqu'à 5 niveaux), avec possibilité de navigation entre le plus général et le plus particulier. En technique informatique, cela implique d'utiliser la DTD$\mathrm{EAD}$, un langage adapté aux exigences de ces normes archivistiques. Le logiciel choisi fut «Pléade 3 » qui permet également, le cas échéant, de visionner des images numériques attachées aux descriptions d'archives.

4 L'enjeu de cette transcription du guide papier sur internet, en effet, était bien dans la possibilité d'y attacher un jour les images des documents eux-mêmes, au fur et à mesure de leur numérisation (les journaux de bord des navires négriers, par exemple).

5 Mais le projet était plus ambitieux encore : une deuxième évolution prévue était de développer cette rubrique du site des Archives de France en un portail redirigeant vers d'autres sites concernant la thématique de l'esclavage, et notamment vers les nombreux produits pédagogiques, ou les expositions virtuelles, élaborés par les services d'archives des départements ayant été marqués par l'histoire de la traite. Parmi les idées de développement de ce portail figurait l'édition d'actes de colloques sur la traite négrière et 
même un module généalogique permettant d'aider à la recherche d'une ascendance esclave.

Mais seule la première phase a été réalisée en 2009 : la mise en ligne de la seule partie instrument de recherche du guide, dépouillée de ses introductions historiques et annexes (glossaire, repères chronologiques, et une fiche très détaillée d'aide à la recherche généalogique d'une ascendance esclave réalisée par Dominique Taffin, directrice des archives de la Martinique).

7 Aujourd'hui, en 2011, faute de moyens essentiellement, nous sommes toujours à ce point et force est de constater que le site est relativement peu visité (200 à 300 visiteurs par mois). Il faut dire que sa mise en ligne n'a donné lieu à aucune communication.

Or, ce site ou plutôt cette rubrique du site des Archives de France consacrée aux sources de la traite négrière et de l'esclavage se trouve à la croisée de deux projets différents, qui ne convergent d'ailleurs pas forcément mais qui ne s'opposent pas non plus.

9 1) le premier est le projet de grand portail des patrimoines de la traite négrière. Ce projet porté par le Département du pilotage de la recherche de la Direction générale des patrimoines est encore dans sa phase d'étude. Il reprend les ambitions premières du site des Archives de France mais élargies à l'ensemble des patrimoines, notamment au patrimoine muséal et ethnographique. Cette approche patrimoniale, cependant, risque de mettre un peu de côté l'aspect proprement historique de la recherche sur la traite et l'esclavage, en promouvant les seuls objets patrimoniaux.

10 2) le deuxième projet est celui de créer un portail unique d'accès aux ressources archivistiques de la France. Ce projet, validé par le Premier ministre dans le cadre de la réforme générale des politiques publiques (RGPP) permettra une navigation dans la description de tous les fonds d'archives publiques, un regroupement de tous les instruments de recherche ou inventaires de tous les centres d'archives, avec, le cas échéant, l'accès aux documents numérisés liés à leur description. Il y aura cependant des dossiers thématiques, comme celui de la traite négrière et de l'esclavage permettant d'accéder aux descriptions des documents qui y sont relatifs : la teneur du guide des sources sera donc préservée, et même enrichie, au sein de ce portail.

11 Une étude fine devra cependant être faite pour assurer une bonne complémentarité entre les deux projets et non un dédoublement.

\section{AUTEUR}

\section{JEAN-BAPTISTE AUZEL}

Chef du bureau de l'accès aux archives - Archives de France jean-baptiste.auzel@culture.gouv.fr 